\title{
KINERJA KEUANGAN BANK SYARIAH DI ASEAN i]
}

\author{
Yessy Listiyanti \\ Mahasiswa Program Studi S1 Ekonomi Islam-Fakultas Ekonomi dan Bisnis-Universitas Airlangga \\ Email: yessy.listiyanti-13@feb.unair.ac.id
}

Atina Shofawati

Departemen Ekonomi Syariah-Fakultas Ekonomi dan Bisnis-Universitas Airlangga

Email: atina-o@feb.unair.ac.id

\begin{abstract}
ABTRACT:
The aims of this research is to determine differences in financial performance between Bank Islam Malaysia Berhad, Bank Syariah Mandiri, and Bank Islam Brunei Darussalam span from the period of 2011 to 2016. This study is a type of comparative research. Financial ratios used in this study are Non Performing Financing (NPF), Financing to Deposit Ratio (FDR), Return on Assets (ROA), Return on Equity (ROE), and Capital Adequacy Ratio (CAR). The statistical model used to test the hypothesis is the one-way ANOVA parametric test. The results showed that there were significant differences in all financial ratio indicators between the performance of Bank Islam Malaysia Berhad, Bank Syariah Mandiri, and Bank Islam Brunei Darussalam except ROA.
\end{abstract}

\section{Keywords: Islamic Bank, Financial Performance, ASEAN}

\section{PENDAHULUAN}

\section{Latar Belakang}

Masyarakat Ekonomi ASEAN (MEA)

atau ASEAN Economic Community merupakan salah satu usaha untuk mewujudkan integrasi ekonomi negaranegara di kawasan ASEAN, yakni tercapainya wilayah ASEAN yang aman dengan tingkat dinamika pembangunan yang lebih tinggi dan terintegrasi, pengentasan masyarakat ASEAN dari kemiskinan, serta pertumbuhan ekonomi untuk mencapai kemakmuran yang merata dan berkelanjutan. MEA memiliki empat karakteristik utama, yaitu pasar tunggal dan basis produksi, kawasan ekonomi yang berdaya saing tinggi, dan kawasan dengan pembangunan ekonomi yang merata, serta kawasan yang terintegrasi penuh dengan ekonomi global (www.kemenlu.go.id, 2015). Salah satu upaya dalam menciptakan sebuah telah diuji pada 9 Agustus 2017

kawasan ekonomi yang berdaya saing tinggi ialah dengan meningkatkan kerjasama di bidang keuangan.

Sektor keuangan yang menjadi salah satu sektor penting dan mempunyai pengaruh yang besar dalam kesepakatan MEA adalah bank. Bank sebagai lembaga intermediasi antara surplus unit dengan defisit unit memiliki peran penting dalam keberlangsungan kegiatan investasi di masyarakat (Kasmir, 2008:2). Berdasarkan cara penentuan harga, bank dapat dibedakan menjadi bank konvensional dan bank syariah (Ismail, 2011:13). Definisi bank syariah sebagaimana yang tercantum dalam undang-undang nomor 21 tahun 2008 Pasal 1 Ayat (7) adalah bank yang dalam menjalankan kegiatan usahanya berdasarkan prinsip syariah, yakni prinsip-prisip dalam bermuamalah yang bersumber dari Al-Qur'an dan hadist. Kehadiran bank syariah sangat 
Listiyanti, et al/Jurnal Ekonomi Syariah Teori dan Terapan Vol. 5 No. 12 Desember 2018: 1023-1027;

KINERJA KEUANGAN BANK SYARIAH DI ASEAN

erat kaitannya dengan adanya pelarangan praktik riba dalam masyarakat, sebagaimana yang sering dilakukan oleh kaum Jahiliyah dulu. Allah SWT berfirman dalam Al-Qur'an surat AlImran ayat 130.

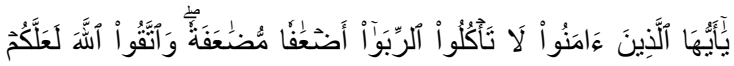
تُفْلِحُونَ

Yā 'Ayyuhā al-Lażīna 'Āmanū lā Ta'kulū arribā aḍ'fan muḍāaftun wattaqū allāha la "alla kum tuflihūna.

Artinya : Hai orang-orang yang beriman, janganlah kamu memakan riba dengan berlipat ganda dan bertakwalah kamu kepada Allah supaya kamu mendapat keberuntungan. (Depag, 2010:66).

Berdasarkan Tafsir Al-Mishbah,

Shihab dalam Tafsir Al-Misbah (2009:257) menjelaskan bahwa,

Surat Al-Imran ayat 130 ini mengajak orang-orang beriman agar tidak memakan riba sebagaimana yang sering terjadi dalam masyarakat Jahiliah ketika itu, yakni yang berlipat ganda. Mereka diajak untuk menghindari siksa Allah di dunia dan di akhirat agar mendapat keberuntungan di dunia dan di akhirat. Salah satu caranya yakni dengan menghindari riba, karena sesungguhnya neraka disediakan bagi orang yang menghalalkan riba.

Dampak-dampak negatif yang diakibatkan oleh riba melatarbelakangi terselenggaranya konferensi \| yang diselenggarakan di Universitas Al-Azhar, Kairo. Ulama-ulama besar dunia yang terhimpun dalam Konsul Kajian Islam Dunia (KKID) telah memutuskan hukum yang tegas terhadap bunga bank. Bahwa tidak ada keraguan atas keharaman praktik pembungaan vang seperti yang dilakukan bank-bank konvensional (Antonio, 2007:66). Bank syariah hadir sebagai solusi bagi masyarakat agar mendapatkan layanan jasa perbankan tanpa adanya unsur riba maupun unsurunsur lainnya yang dilarang dalam Islam.

Kawasan ASEAN memiliki potensi yang besar dalam pengembangan perbankan syariah dunia. Hal ini dikarenakan populasi penduduk beragama Islam di ASEAN yang besar. Terdapat dua negara anggota ASEAN yang masuk kategori negara dengan populasi muslim terbesar di dunia, yakni Indonesia dengan jumlah \pm 205.000 .000$ jiwa dan Malaysia \pm 17.000 .000 jiwa (KFH Research, 2013:6). Potensi inilah yang seharusnya dilakukan optimalisasi dengan baik dalam pengembangan perbankan syariah di kawasan ASEAN.

Menurut Ernst dan Young (2014), pertumbuhan total aset keuangan syariah pada bank komersial tahun 2009-2013 mengalami kenaikan sebesar $17 \%$ dengan total aset pada tahun 2013 sebesar US\$778 miliyar. Pada tahun 2013, Aset negara-negara anggota ASEAN menempati peringkat kedua dengan aset sebesar US\$160 milyar. Aset yang senantiasa meningkat setiap tahunnya, menimbulkan optimisme bagi perkembangan perbankan syariah di ASEAN.

MEA sejatinya mulai diberlakukan pada tahun 2015, namun untuk sektor 
Listiyanti, et al/Jurnal Ekonomi Syariah Teori dan Terapan Vol. 5 No. 12 Desember 2018: 1023-1027; KINERJA KEUANGAN BANK SYARIAH DI ASEAN

perbankan dan keuangan, MEA mulai berlaku pada tahun 2020. Pemberlakuan MEA pada sektor perbankan nantinya akan memberikan berbagai dampak bagi sektor perbankan di masing-masing negara. Salah satunya yaitu banyaknya tenaga kerja asing. Penambahan tenaga kerja asing tidaklah bisa dihindari, karena pasar yang dituju tidak hanya pasar lokal tapi juga pasar ASEAN dengan latar belakang dan budaya masing-masing sehingga dengan penambahan tenaga kerja asing diharapkan bank dapat lebih mengetahui karakteristik pasar dan lebih mudah dalam mengambil pasar negara tersebut nantinya. Selain itu, dari segi pasar modal, adanya ASEAN Collective Investment scheme (ASEAN CIS) yaitu suatu kerangka kerja yang mengizinkan negara-negara yang berpartisipasi didalamnya untuk menawarkan produk pasar modal yang telah memenuhi standar yang ditetapkan bersama. Berlakunya ASEAN CIS, nantinya akan menjadikan banyaknya investor asing yang menanamkan modalnya. Ini bisa menjadi suatu peluang apabila bank mempunyai kemampuan yang baik dalam pengelolaan modal tersebut, namun apabila bank tersebut gagal dalam mengelolah modal yang diberikan maka akan menjadikan kondisi yang berbahaya bagi bank tersebut. Bagi Industri Perbankan, tantangan lain yang harus dihadapi adalah masuk tidaknya suatu bank dalam Qualified ASEAN Bank (QAB). QAB menjadi sangat penting bagi suatu bank, karena apabila suatu bank sudah berhasil mendapatkan kualifikasi tersebut, maka bank akan diberikan hak untuk melakukan ekspansi ke berbagai negara anggota ASEAN. Tentu saja hal tersebut akan sangat menguntungkan bagi bank yang masuk dalam kategori $Q A B$, namun juga akan sangat merugikan bagi bank yang tidak masuk kategori $Q A B$, karena pasar yang selama ini dimilikinya akan terbagi seiring dengan semakin banyaknya bank asing yang beroperasi di wilayah pasarnya (Rudiyanto, 2016). Tentu saja hal-hal tersebut menjadi tantangan yang besar bagi bank di kawasan ASEAN untuk senantiasa meningkatkan kinerjanya, sehingga bank-bank tersebut nantinya dapat memanfaatkan pemberlakuan MEA untuk mengambil pangsa pasar baru di kawasan ASEAN yang sebanyakbanyaknya dan menjadikan MEA sebagai hal yang menguntungkan.

Persaingan antar bank syariah maupun dengan bank konvensional yang semakin ketat menuntut agar bank syariah mempunyai kinerja keuangan yang baik agar dapat memperebutkan pasar perbankan di negara anggota ASEAN, terlebih di era MEA saat ini. Kinerja keuangan bank merupakan gambaran kondisi keuangan bank pada suatu periode tertentu baik mencakup aspek penghimpunan dana maupun penyaluran dananya. Kinerja menunjukan sesuatu yang berhubungan dengan kekuatan serta kelemahan suatu perusahaan. Kekuatan tersebut dipahami agar dapat dimanfaatkan dan kelemahan pun harus 
Listiyanti, et al/Jurnal Ekonomi Syariah Teori dan Terapan Vol. 5 No. 12 Desember 2018: 1023-1027; KINERJA KEUANGAN BANK SYARIAH DI ASEAN

diketahui agar dapat dilakukan langkahlangkah perbaikan (Lestari dan Sugiharto, 2007:31).

\section{RUMUSAN MASALAH}

Berdasarkan uraian latar belakang di atas maka rumusan masalah yang dapat dibuat adalah:

1. Apakah terdapat perbedaan kinerja kevangan yang signifikan antara BIMB, BSM, dan BIBD tahun 2011-2016 menggunakan rasio NPF?

2. Apakah terdapat perbedaan kinerja kevangan yang signifikan antara BIMB, BSM, dan BIBD tahun 2011-2016 menggunakan rasio FDR?

3. Apakah terdapat perbedaan kinerja kevangan yang signifikan antara BIMB, BSM, dan BIBD tahun 2011-2016 menggunakan rasio ROA?

4. Apakah terdapat perbedaan kinerja kevangan yang signifikan antara BIMB, BSM, dan BIBD tahun 2011-2016 menggunakan rasio ROE?

5. Apakah terdapat perbedaan kinerja keuangan yang signifikan antara BIMB, BSM, dan BIBD tahun 2011-2016 menggunakan rasio CAR?

\section{LANDASAN TEORI}

\section{Kinerja Keuangan}

Kinerja keuangan merupakan suatu analisis dengan menggunakan aturanaturan pelaksanaan kevangan secara baik dan benar yang digunakan untuk melihat tata kelola keuangan suatu perusahaan (Fahmi, 2011:2). Definisi tersebut menjelaskan bahwa dalam menganalisis kinerja keuangan suatu perusahaan dibutuhkan aturan-aturan yang jelas sebagai pedoman. Aturanaturan yang jelas dibuat guna menyeragamkan penilaian kinerja kevangan suatu bank.

Menurut Jumingan (2006:239) kinerja kevangan adalah gambaran kondisi keuangan perusahaan pada suatu periode tertentu baik menyangkut aspek penghimpunan dana maupun penyaluran dana, yang biasanya diukur dengan indikator kecukupan modal, likuiditas, dan profitabilitas. Berdasarkan Pendapatpendapat tersebut diatas dapat disimpulkan bahwa kinerja keuangan adalah cerminan dari baik atau buruknya kondisi keuangan suatu perusahaan pada suatu periode tertentu yang diukur melalui proses analisis dengan menggunakan indikator keuangan.

Kinerja keuangan perusahaan sangat erat kaitannya dengan pengukuran dan penilaian kinerja. Adapun penilaian kinerja menurut Srimindarti (2006:34) adalah penentuan efektivitas operasional, organisasi, dan karyawan berdasarkan sasaran, standar dan kriteria yang telah ditetapkan sebelumnya secara periodik.

Kasmir (2015:106) menyatakan bahwa kinerja kevangan suatu bank syariah dapat dinilai dengan menggunakan beberapa rasio keuangan. Masing-masing rasio keuangan memiliki tujuan, kegunaan, dan arti tertentu. Hasil perhitungan rasio tersebut kemudian diinterpretasikan sehingga memunculkan suatu kesimpulan yang bisa digunakan sebagai pertimbangan dalam 
Listiyanti, et al/Jurnal Ekonomi Syariah Teori dan Terapan Vol. 5 No. 12 Desember 2018: 1023-1027; KINERJA KEUANGAN BANK SYARIAH DI ASEAN

pengambilan keputusan oleh para pemangku kepentingan.

Analisis rasio keuangan dapat dilakukan dengan menganalisis posisi neraca dan laporan laba rugi baik secara individu maupun secara simultan. Menurut Muhamad (2015:252) rasio keuangan bank terdiri dari rasio likuiditas, rasio aktivitas, rasio profitabilitas, dan rasio biaya.

\section{Analisis Rasio Kevangan Bank Syariah}

Berikut ini merupakan rasio-rasio kevangan untuk menganalisis kinerja keuangan bank syariah:

\section{Non Performing Financing}

Non performing financing (NPF) merupakan rasio yang untuk menilai kemampuan manajemen bank dalam mengelola pembiayaan yang diberikan kepada nasabah. Penggolongan NPF didasarkan pada ketepatan nasabah dalam membayarkan kewajibannya, baik margin maupun pokok pembiayaan.

\section{Financing to Deposit Ratio}

Financing to deposit ratio (FDR) ialah suatu rasio yang membandingkan proporsi antara jumlah pembiayaan yang diberikan oleh bank dengan jumlah dana pihak ketiga. FDR termasuk dalam kategori rasio likuiditas bank, dimana tinggi rendahnya rasio ini menunjukkan kemampuan bank dalam memenuhi kewajiban jangka pendeknya pada saat ditagih (Kasmir, 2015:221).

\section{Return on Asset}

Return on Asset (ROA) termasuk dalam kategori rasio profitabilitas, yakni rasio yang digunakan untuk mengukur keutungan yang dicapai oleh bank dalam suatu periode tertentu. Rasio ini digunakan untuk mengukur kemampuan sebuah bank dalam memanfaatkan asetnya untuk menciptakan keuntungan dengan cara membandingkan keuntungan dengan asset yang menghasilkan keuntungan tersebut.

\section{Return on Equity}

Return on Equity (ROE) merupakan rasio yang digunakan untuk mengukur dan membandingkan kinerja profitabilitas bank. ROE juga dapat menunjukkan kemampuan bank dalam mengelolah modal yang dimilikinya untuk mendapatkan net income.

\section{Capital Adequacy Ratio}

Penilaian terhadap permodalan bank yakni suatu evaluasi terhadap kecukupan modal dan kecukupan pengelolaan permodalan. Modal bank mempunyai tiga fungsi penting yaitu, pelindung bagi kepentingan deposan apabila bank mengalami kerugian, sebagai dasar penetapan batas maksimum dalam pemberian kredit, serta bisa digunakan para partisipan sebagai dasar dalam mengevaluasi tingkat kemampuan bank secara relatif untuk menghasilkan keuntungan (Muhamad, 2015:249).

Wibowo (2015), dalam penelitian yang berjudul "Analisis Perbandingan Kinerja Kevangan Perbankan Syariah dengan Metode Camel di ASEAN (Studi Komparatif: Indonesia, Malaysia, Thailand)". Kriteria yang digunakan dalam penelitian tersebut adalah Capital To Assets (CCA), Capital Adequacy Ratio 
Listiyanti, et al/Jurnal Ekonomi Syariah Teori dan Terapan Vol. 5 No. 12 Desember 2018: 1023-1027;

KINERJA KEUANGAN BANK SYARIAH DI ASEAN

(CAR), Non-Performing Loan (NPL), Employee Expenses to total Assets (EEA), Loan-to-Deposit Ratio (LDR), Return On Assets (ROA), Return On Equity (ROE), serta Assets Growth Rate (AGR). Penelitian tersebut menggunakan CAMEL dan uji statistik One-Way ANOVA.

Hasil uji statistik menunjukkan bahwa ratio dari semua indikator keuangan perbankan Islam di Indonesia berbeda secara signifikan dengan di Malaysia dan Thailand serta tidak ada yang ditunjukkan secara signifikan.

\section{HIPOTESIS PENELITIAN}

Berdasarkan rumusan masalah dan uraian yang terdapat pada $B A B 1$ dan $B A B$ 2, maka hipotesis dari penelitian ini adalah :

$\mathrm{H}_{1}$ : Terdapat perbedaan kinerja keuangan yang signifikan antara BIMB, BSM, dan BIBD tahun 2011-2016 menggunakan rasio NPF.

$\mathrm{H}_{2}$ : Terdapat perbedaan kinerja keuangan yang signifikan antara BIMB, BSM, dan BIBD tahun 2011-2016 menggunakan rasio FDR.

$\mathrm{H}_{3}$ : Terdapat perbedaan kinerja kevangan yang signifikan antara BIMB, BSM, dan BIBD tahun 2011-2016 menggunakan rasio $\mathrm{ROA}$.

$\mathrm{H}_{4}$ : Terdapat perbedaan kinerja keuangan yang signifikan antara BIMB, BSM, dan BIBD tahun 2011-2016 menggunakan rasio ROE.

$\mathrm{H}_{5}$ : Terdapat perbedaan kinerja keuangan yang signifikan antara BIMB, BSM, dan BIBD tahun 2011-2016 menggunakan rasio CAR.

\section{METODE PENELITIAN}

Pendekatan Penelitian

Penelitian ini berusaha untuk membandingkan kinerja kevangan antara BIMB, BSM, dan BIBD dengan menggunakan laporan keuangan masing-masing bank tahun 2011, 2012, 2013, 2014, 2015, dan 2016. Pendekatan yang digunakan dalam penelitian ini adalah kuantitatif. Statistik deskriptif digunakan dalam menganalisis data dengan cara mendeskripsikan data yang telah terkumpul. Alat uji statistik yang digunakan adalah uji One-Way Anova dengan menggunakan alat software SPSS 20.

\section{Jenis dan Sumber Data}

Data laporan keuangan tahunan bank syariah yang menjadi data sekunder dalam penelitian ini diperoleh dari beberapa sumber seperti laporan keuangan publikasi yang ada di situs www.ojk.go.id, www.bi.go.id, www.bnm.gov.my, www.ambd.gov.bn, dan situs resmi masing-masing bank.

\section{Populasi dan Sampel}

Populasi dalam penelitian ini adalah Bank Umum Syariah yang ada di Malaysia, Indonesia, dan Brunei Darussalam. Sampel data dalam penelitian ini ditentukan menggunakan teknik purposive sampling dan terdapat 1 bank syariah di masing-masing negara yang memenuhi kriteria pengambilan sampel. Sehingga, jumlah sampel yang digunakan sebanyak 3 bank syariah, yakni Bank Islam Malaysia Berhad, Bank Syariah 
Listiyanti, et al/Jurnal Ekonomi Syariah Teori dan Terapan Vol. 5 No. 12 Desember 2018: 1023-1027; KINERJA KEUANGAN BANK SYARIAH DI ASEAN

Mandiri, dan Bank Islam Brunei Darussalam.

\section{Teknik Analisis Data}

\section{Analisis Statistik Deskriptif}

Menurut Anshori dan Iswati (2009:1 16) statistik deskriptif adalah statistik yang digunakan untuk menganalisis data yang telah terkumpul sebagaimana adanya tanpa bermaksud membuat kesimpulan yang berlaku untuk umum atau generalisasi. Analisis statistik deskriptif berfungsi menggambarkan data sampel serta memberikan deskripsi variabel.

\section{Uji Asumsi Klasik}

\section{Uji Normalitas}

Uji normalitas digunakan untuk menguji apakah data terdistribusi normal atau tidak. Normalitas dapat dideteksi dengan melihat histogram dan residualnya (Ghozali, 2006:112). Pengujian terhadap normalitas dapat menggunakan Kolmogorov-Smirnov Test.

\section{Uji Homogenitas}

Uji homogenitas digunakan untuk menguji apakah sebuah grup mempunyai varians yang sama di antara anggota grup (Santoso, 2014:48). Jika varians sama, dan ini yang seharusnya terjadi, maka dikatakan ada homogenitas. Sedangkan jika varians tidak sama, maka dikatakan terjadi heterogenitas. Menguji homogenitas dapat dilakukan dengan menggunakan alat analisis Levene Test.

\section{Uji Hipotesis}

\section{Uji ANOVA}

Analisis of variance (ANOVA) merupakan suatu metode statistika yang berfungsi untuk mengkaji (mendeterminasi) apakah rata-rata hitung (mean) dari tiga populasi atau lebih, sama atau tidak. Penelitian ini menggunakan uji parametrik One-Way ANOVA dengan tingkat signifikansi $a=$ 0,05. Menurut Ghozali (2011:70) Beberapa asumsi yang harus dipenuhi dalam melakukan nnalisis One-Way ANOVA ialah sebagai berikut :

a. Populasi yang akan diuji berdistribusi normal

b. Seluruh sampel adalah independen

c. Terdapat variance dari populasipopulasi yang akan diuji

d. Sampel yang akan diuji tidak berhubungan satu dengan yang lain.

\section{Uji Post Hoc Test}

Uji Post Hoc Test dilakukan untuk melihat besar perbedaan kinerja keuangan bank syariah di ASEAN, dengan melihat pada output Tukey test dan Bonferoni test. Pada sampel yang sama, menggunakan output Tukey test. Sedangkan pada sampel yang berbeda menggunakan Bonferoni test. Jika terdapat tanda "*" pada kolom mean difference, berarti terdapat perbedaan yang signifikan (Webster, 1998).

\section{Hasil dan Pembahasan}

\section{Statistik Deskriptif}

Berdasarkan data yang ada pada Tabel 1 dapat dilihat bahwa untuk data NPF memiliki rata-rata sebesar 3,11 dan standar deviasi sebesar 1,99 dengan nilai maksimal sebesar 7,40 dan nilai minimal sebesar 0,95, data FDR memiliki rata-rata sebesar 67,75 dan standar deviasi sebesar 18,49 dengan nilai maksimal sebesar 94,40 
Listiyanti, et al/Jurnal Ekonomi Syariah Teori dan Terapan Vol. 5 No. 12 Desember 2018: 1023-1027; KINERJA KEUANGAN BANK SYARIAH DI ASEAN

dan nilai minimal sebesar 36,58, data ROA memiliki rata-rata sebesar 1,45 dan standar deviasi sebesar 0,57 dengan nilai maksimal 2,25 dan nilai minimal $-0,04$, data ROE memiliki rata-rata sebesar 13,32 dan standar deviasi sebesar 7,47 dengan nilai maksimal sebesar 25,05 dan nilai minimal sebesar -0,94 dan data CAR memiliki ratarata sebesar 17,72 dan standar deviasi sebesar 5,08 dengan nilai maksimal sebesar 27,30 dan nilai minimal sebesar 12,85 .

\section{Tabel 1}

Statistik Deskriptif

\begin{tabular}{|l|l|l|l|l|}
\hline Var. & Mean & Std. & Min. & Max. \\
\hline NPF & 3.1056 & 1.99314 & 0.95 & 7.40 \\
\hline FDR & 67.7528 & 18.49306 & 36.58 & 94.40 \\
\hline ROA & 1.4450 & 0.56642 & -0.04 & 2.25 \\
\hline ROE & 13.3289 & 7.47535 & -0.94 & 25.05 \\
\hline CAR & 17.7150 & 5.07584 & 12.85 & 27.30 \\
\hline
\end{tabular}

\section{Uji Normalitas}

Hasil uji normalitas berdasarkan Kolmogorov Smirnov didapatkan sig. untuk data NPF sebesar 0,666 , data FDR sebesar 0,352 , data ROA sebesar 0,117 , data ROE sebesar 0,731 dan data CAR sebesar 0,123 dimana semua nilai sig. tersebut lebih besar dari 0,05, Kesimpulan yang didapat ialah bahwa semua data berdistribusi normal, sehingga asumsi normalitas terpenuhi.

\section{Uji Homogenitas}

Hasil uji homogenitas data didapatkan sig. untuk data NPF sebesar 0,146, data FDR sebesar 0,655, dimana nilai ini lebih besar dari taraf sig. 0,05. Kesimpulan yang didapatkan ialah untuk merima Hipotesis nol yang berarti bahwa data antar kelompok yang digunakan memiliki varian yang sama atau memenuhi asumsi homogenitas. Data ROA memiliki nilai sig. sebesar 0,000 , data ROE sebesar 0,000 dan data CAR sebesar 0,040 dimana nilai ini lebih kecil dari taraf signifikansi alfa 0,05. Artinya diputuskan untuk menolak Hipotesis nol yang berarti bahwa data antar kelompok yang digunakan memiliki varians yang tidak sama atau tidak memenuhi asumsi homogenitas. Menurut Box (1954) menyatakan bahwa ANOVA masih tetap dapat digunakan oleh karena ANOVA robust untuk penyimpangan yang kecil dari homogeneity of variance.

\section{Uji Hipotesis}

\section{Uji ANOVA}

Uji ANOVA berikut dilakukan untuk mengetahui ada atau tidaknya perbedaan rata-rata yang signifikan antara kinerja keuangan $\mathrm{BIMB}, \mathrm{BSM}<$ dan BIBD dengan menggunakan rasio NPF, FDR, ROA, ROE, dan CAR. Berikut adalah hasil Uji ANOVA yang diperoleh.

Tabel 2

Uji ANOVA

\begin{tabular}{|c|c|}
\hline Variabel & Sig. \\
\hline NPF & 0,000 \\
\hline FDR & 0,000 \\
\hline ROA & 0,279 \\
\hline ROE & 0,031 \\
\hline CAR & 0,000 \\
\hline
\end{tabular}

Hasil uji ANOVA pada tabel 2 di atas, terlihat bahwa semua variabel memiliki nilai signifikansi sebesar $<0,05$, kecuali variabel ROA. Hal ini menunjukan adanya perbedaan kinerja kevangan antara BIMB, BSM, dan BIBD tahun 20112016 menggunakan rasio NPF, FDR, ROE, dan CAR. Sedangkan, berdasarkan rasio 
Listiyanti, et al/Jurnal Ekonomi Syariah Teori dan Terapan Vol. 5 No. 12 Desember 2018: 1023-1027;

KINERJA KEUANGAN BANK SYARIAH DI ASEAN

ROA tidak terlihat adanya perbedaan kinerja keuangan yang signifikan.

Uji Post Hoc Test

Hasil Post Hoc Test menunjukan yang telah dilakukan menunjukan bahwa berdasarkan tingkat signifikansinya, terdapat perbedaan yang signifikan antara BSM dengan BIBD, serta BIBD dengan BIMB apabila ditinjau dari rasio NPF. NPF akan mencerminkan kemampuan bank syariah dalam mengelola pembiayaan bermasalah.

Tingkat signifikansi pada Tabel 3 menunjukan bahwa berdasarkan nilai FDR, keseluruhan grup bank syariah tersebut mempunyai perbedaan yang signifikan.

Berdasarkan rasio ROA, terlihat pada BIMB dengan BSM terdapat perbedaan rata-rata 0,42167. Perbedaaan rata-rata antara bank syariah Indonesia dengan BIBD sebesar $-0,49333$. BIBD dengan BSM juga mempunyai perbedaan rata-rata 0,07167. Berdasarkan tingkat signifikansinya, tidak terdapat perbedaan yang signifikan antara ketiga grup tersebut apabila dilihat dari rasio ROA. Berbeda dengan uji berdasarkan rasio $R O E$, yang menunjukan hasil BIBD dan BIMB mempunyai perbedaan yang signifikan.

Tingkat signifikansi pada Tabel 3 menunjukan bahwa terdapat perbedaan yang signifikan antara BSM dengan BIBD. Demikian pula dengan BIBD dengan BIMB, terlihat pada keduanyan juga terdapat perbedaan yang signifikan berdasarkan nilai CAR yang dimilikinya.

Tabel 3

\section{Uji Post Hoc Test}

\begin{tabular}{|l|l|l|r|r|r|}
\hline Var. & $\begin{array}{c}\text { (I) } \\
\text { Bank }\end{array}$ & $\begin{array}{c}\text { (J) } \\
\text { Bank }\end{array}$ & $\begin{array}{c}\text { Mean Dif. } \\
(\mathrm{I}-\mathrm{J})\end{array}$ & \multicolumn{1}{c|}{ Std. } & Sig. \\
\hline NPF & BIMB & BSM & $-1,21667$ &, 69451 &, 219 \\
\hline & BSM & BIBD & $-2,60833^{*}$ &, 69451 &, 005 \\
\hline & BIBD & BIMB & $3,82500^{*}$ &, 69451 &, 000 \\
\hline FDR & BIMB & BSM & $-12,9133^{*}$ & 3,97086 &, 014 \\
\hline & BSM & BIBD & $40,38333^{*}$ & 3,97086 &, 000 \\
\hline & BIBD & BIMB & $-27,4700^{*}$ & 3,97086 &, 000 \\
\hline ROA & BIMB & BSM &, 42167 &, 31977 &, 407 \\
\hline & BSM & BIBD &,- 49333 &, 31977 &, 300 \\
\hline & BIBD & BIMB &, 07167 &, 31977 &, 973 \\
\hline ROE & BIMB & BSM & 6,51333 & 3,64571 &, 208 \\
\hline & BSM & BIBD & 4,23667 & 3,64571 &, 493 \\
\hline & BIBD & BIMB & $-10,7500^{*}$ & 3,64571 &, 025 \\
\hline CAR & BIMB & BSM &, 97167 &, 93035 &, 561 \\
\hline & BSM & BIBD & $-10,4383^{*}$ &, 93035 &, 000 \\
\hline & BIBD & BIMB & $9,46667^{*}$ &, 93035 &, 000 \\
\hline
\end{tabular}

\section{Pembahasan}

Deskripsi penelitian menunjukan adanya peningkatan dan penurunan nilai rasio keuangan pada tahun 2011-2016.

\section{Non Performing Financing}

Berikut merupakan data nilai rasio pada BIMB, BSM, dan BIBD pada tahun 2011-2016:

\section{Tabel 4}

\section{Nilai Rasio NPF pada BIMB, BSM, dan BIBD}

\begin{tabular}{|c|c|c|c|}
\hline Tahun & BIMB & BSM & BIBD \\
\hline 2011 & $2,61 \%$ & $0,95 \%$ & $3,40 \%$ \\
\hline 2012 & $1,55 \%$ & $1,14 \%$ & $4,10 \%$ \\
\hline 2013 & $1,18 \%$ & $2,29 \%$ & $7,40 \%$ \\
\hline 2014 & $1,14 \%$ & $4,29 \%$ & $5,50 \%$ \\
\hline 2015 & $1,09 \%$ & $4,05 \%$ & $5,40 \%$ \\
\hline 2016 & $0,98 \%$ & $3,13 \%$ & $5,70 \%$ \\
\hline Mean & $\mathbf{1 , 4 2 \%}$ & $\mathbf{2 , 6 4 \%}$ & $\mathbf{5 , 2 5 \%}$ \\
\hline
\end{tabular}

Pada tabel 4 di atas menunjukan

bahwa rata-rata NPF tertinggi adalah BIBD, kemudian BSM, dan BIMB. Rendahnya rasio NPF BIMB mempunyai nilai rata-rata paling rendah diantara bank syariah di dua negara anggota ASEAN lainnya. Rendahnya nilai NPF BIMB menunjukan bahwa pembiayaan bermasalah di Malaysia sangat kecil dan 
Listiyanti, et al/Jurnal Ekonomi Syariah Teori dan Terapan Vol. 5 No. 12 Desember 2018: 1023-1027; KINERJA KEUANGAN BANK SYARIAH DI ASEAN

membuktikan tingginya kesadaran para nasabahnya untuk membayar kewajibannya. Semakin rendah rasio NPF yang dimiliki oleh suatu bank syariah, maka menunjukan kualitas aktiva produktif yang baik dan menjadikan kemampuan bank dalam menciptakan pendapatan operasional lebih tinggi.

Kemampuan BIMB yang baik dalam mengelola pembiayaan bermasalah, salah satunya disebabkan oleh pengalaman yang lebih lama dalam mengatasi hal tersebut Jika dibandingkan dengan BSM dan BIBD. Bank Islam Malaysia telah berdiri sejak 1983, sedangkan BSM dan BIBD yang baru berdiri pada tahun 1999 dan 2005.

Tren fluktuasi yang dialami BSM dan BIBD tersebut dikarenakan terjadinya fluktuasi tingkat inflasi di masing-masng negara. Berdasarkan data dari (www.indonesia-investments.com, 2016), pada tahun 2013 dan 2014 terjadi kenaikan tingkat inflasi yang cukup drastis di Indonesia yakni pada tahun 2012 tingkat inflasi hanya sebesar $4,3 \%$, lalu meningkat secara tajam pada tahun 2013 sebesar $8,4 \%$. Begitu pula pada tahun 2014 yang tetap bertahan pada angka $8,4 \%$. Namun, pada tahun 2015 tingkat inflasi mengalami penurunan yang drastis sebesar 3,4\% dan berada pada posisi 3,0\% pada tahun 2016. Pola kenaikan dan penurunan ini sama halnya dengan pola nilai NPF yang dialami BSM pada tabel 4. Terlihat bahwa tahun 2013 nilai NPF mengalami kenaikan yang cukup drastis yakni sebesar $2,29 \%$ dan sebesar $4,29 \%$ pada tahun 2014. Seperti halnya turunnya tingkat inflasi pada tahun 2015 dan tahun 2016, nilai NPF juga memiliki kecenderungan untuk turun pada tahun tersebut. Tidak berbeda jauh dengan BSM, BIBD juga mengalami pola NPF yang sama dengan pola fluktuasi tingkat inflasinya. Berdasarkan data yang diambil dari (www.focus-economics.com, 2017), dapat diketahui bahwa pada tahun 2012 tingkat inflasi di Brunei Darussalam mengalami perubahan sebesar $0,1 \%$ dibandingkan dengan tahun sebelumnya. Begitu pula pada tahun 2013, terjadi perubahan tingkat inflasi sebesar $0,4 \%$ jika dibandingkan tahun 2012. Sedangkan pada tahun 2014, 2015, dan 2016 tingkat inflasi di Brunei Darussalam cenderung mengalami penurunan. Secara berturutturut, besar perubahan penurunan tingkat inflasi yang terjadi pada tahun 2014, 2015, dan 2016 yakni $-0,2 \%$, $-0,4 \%$, dan $-0,7 \%$. Senada dengan hal tersebut, nilai NPF BIBD yang terlihat pada gambar 4.1 menunjukan kenaikan yang cukup drastis pada tahun 2012 dan tahun 2013, serta mengalami penurunan pada tahun sesudahnya. Hasil ini sesuai dengan penelitian yang dilakukan oleh Saniati (2015) yang menyebutkan bahwa inflasi positif berpengaruh signifikan terhadap NPF. Ketika suatu negara mengalami inflasi yang tinggi, maka akan berdampak pada meningkatnya tingkat suku bunga. Kondisi tersebut akan menyebabkan melemahnya kondisi ekonomi suatu negara karena masyarakat mempunyai kecenderungan untuk menyimpan 
Listiyanti, et al/Jurnal Ekonomi Syariah Teori dan Terapan Vol. 5 No. 12 Desember 2018: 1023-1027; KINERJA KEUANGAN BANK SYARIAH DI ASEAN

vangnya di bank dibandingkan memelanjakannya untuk kegiatan konsumsi. Hal inilah yang akan menghambat usaha yang dilakukan oleh nasabah yang melakukan pembiayaan, sehingga menyebabkan timbulnya non performing financing.

\section{Financing to Deposit Ratio}

Data pada Tabel 5 menunjukan bahwa BSM mempunyai nilai Rata-rata FDR tertinggi. Berbeda dengan BIMB dan BIBD menempati posisi kedua dan ketiga. Nilai rata-rata FDR yang tinggi mencerminkan bahwa BSM telah berhasil menyalurkan dana deposito atau dana pihak ketiga utuk pembiayan secara baik.

\section{Tabel 5}

Nilai FDR pada BIMB, BSM, dan BIBD

\begin{tabular}{|c|c|c|c|}
\hline Tahun & BIMB & BSM & BIBD \\
\hline 2011 & $78,64 \%$ & $86,03 \%$ & $37,89 \%$ \\
\hline 2012 & $61,28 \%$ & $94,40 \%$ & $44,96 \%$ \\
\hline 2013 & $65,09 \%$ & $89,37 \%$ & $52,81 \%$ \\
\hline 2014 & $73,42 \%$ & $82,13 \%$ & $44,88 \%$ \\
\hline 2015 & $78,71 \%$ & $81,99 \%$ & $53,69 \%$ \\
\hline 2016 & $78,49 \%$ & $79,19 \%$ & $36,58 \%$ \\
\hline Mean & $72,60 \%$ & $85,52 \%$ & $45,14 \%$ \\
\hline
\end{tabular}

bahwa BSM sedang melakukan tipe manajemen yang bersifat sangat ekspansif atau agresif. Hal ini relevan dengan kondisi yang saat ini terjadi di Indonesia, dimana menurut Otoritas Jasa Keuangan hingga bulan Juli 2016 pertumbuhan pangsa pasar perbankan syariah Indonesia sebesar 4,86\% (www.ekbis.sindonews.com, 2016). Jumlah Market share sebesar itu sangtlah kecil jika dibandingkan dengan persentase penduduk muslim Indonesia yang berjumlah 207.176.162 jiwa atau sebesar
87,18\% (www.bps.go.id, 2010). Latar belakang itulah yang mendorong BSM untuk menyalurkan banyak pembiayaan yang berasal dari dana deposito/dana pihak ketiga, agar semakin banyak masyarakat yang mengenal dan terlibat dalam kegiatan operasional bank syariah. Sehingga market share perbankan syariah di Indonesia dapat meningkat. Namun yang perlu diperhatikan, nilai FDR juga mencerminkan tingkat likuiditas bank, dimana tinggi rendahnya nilai FDR akan menunjukan kemampuan bank dalam memenuhi kewajiban jangka pendeknya pada saat ditagih (Kasmir, 2015:221). Sehingga dengan nilai FDR yang tinggi BSM harus menjaga agar likuiditasnya tetap baik.

\section{Return on Asset}

\section{Tabel 6}

Nilai ROA pada BIMB, BSM, dan BIBD

\begin{tabular}{|c|c|c|c|}
\hline Tahun & BIMB & BSM & BIBD \\
\hline 2011 & $1,57 \%$ & $1,95 \%$ & $1,50 \%$ \\
\hline 2012 & $1,72 \%$ & $2,25 \%$ & $2,20 \%$ \\
\hline 2013 & $1,69 \%$ & $1,53 \%$ & $1,40 \%$ \\
\hline 2014 & $1,59 \%$ & $-0,04 \%$ & $1,50 \%$ \\
\hline 2015 & $1,43 \%$ & $0,56 \%$ & $1,70 \%$ \\
\hline 2016 & $1,37 \%$ & $0,59 \%$ & $1,50 \%$ \\
\hline Mean & $\mathbf{1 , 5 6 \%}$ & $\mathbf{1 , 1 4 \%}$ & $\mathbf{1 , 6 3 \%}$ \\
\hline \multicolumn{2}{|c|}{ Uji ANOVA menunjukan bahwa } \\
\cline { 2 - 4 }
\end{tabular}

tidak terdapat perbedaan kinerja kevangan yang signifikan antara $B I M B, B S M$, dan BIBD. Tidak adanya perbedaan nilai ROA antar bank syariah disebabkan oleh sama-sama masih rendahnya total aset yang dimiliki oleh bank syariah. Hal ini dikarenakan masih terbatasnya market share yang dimiliki oleh bank syariah di masing-masing negara. Market share yang rendah 
Listiyanti, et al/Jurnal Ekonomi Syariah Teori dan Terapan Vol. 5 No. 12 Desember 2018: 1023-1027; KINERJA KEUANGAN BANK SYARIAH DI ASEAN

menyebabkan rendah pula fasilitas yang akan diberikan kepada nasabah (Sukmana dan Febriyati, 2016).

Selain itu, beragamnya produk yang ditawarkan oleh bank syariah dengan berbagai akad yang tidak semuanya memberikan keuntungan yang tetap akan membuat keuntungan bank syariah cenderung fluktuatif. Namun, nilai rata-rata tertinggi diraih oleh BIBD. Tingginya nilai rata-rata ROA, mencerminkan bahwa BIBD mempunyai kemampuan yang baik dalam memanfaatkan aset yang dimilikinya untuk menghasilkan keuntungan. Kemampuan yang baik ini salah satunya didukung dengan market share BIBD yang tinggi yakni sebesar 85\%, sehingga BIBD mempunyai kesempatan yang lebih dalam menyalurkan pembiayaan kepada nasabah begitu pula kesempatan untuk mendapatkan keuntungan yang lebih tinggi.

Hal lain yang dapat mempengaruhi ROA adalah besarnya nilai NPF, semakin besar nilai NPF yang dimiliki maka mencerminkan buruknya kualitas pembiayaan yang diberikan. Ketika kualitas pembiayaan yang dimiliki buruk, maka akan buruk pula kemampuannya untuk menghasilkan keuntungan. Tabel 6 menunjukan anjloknya nilai ROA BSM pada tahun 2014 disebabkan oleh kenaikan secara drastis nilai NPF pada tabel 4. Pada tahun serupa, yaitu sebesar 2,29\% pada tahun 2013 dan meningkat menjadi sebesar $4,29 \%$ pada tahun 2014. Kenaikan tersebut sangat berpengaruh terhadap laba yang didapatkannya. Oleh sebab itulah nilai ROA dan ROE BSM pada tahun 2014 mengalami penurunan yang drastis.

\section{Return on Equity}

Diketahui dari hasil pengujian ANOVA, bahwa ketiga negara tersebut memliki perbedaan yang signifikan. Data pada Tabel 7 menunjukan bahwa bank yang mempunyai nilai rata-rata ROE tertinggi adalah BIMB. BSM berada di peringkat kedua, dan BIBD berada di peringkat ketiga

\section{Tabel 7}

Nilai ROE pada BIMB, BSM, dan BIBD

\begin{tabular}{|c|c|c|c|}
\hline Tahun & BIMB & BSM & BIBD \\
\hline 2011 & $18,51 \%$ & $24,24 \%$ & $8,20 \%$ \\
\hline 2012 & $20,21 \%$ & $25,05 \%$ & $10,20 \%$ \\
\hline 2013 & $21,07 \%$ & $15,34 \%$ & $5,60 \%$ \\
\hline 2014 & $19,92 \%$ & $-0,94 \%$ & $7,50 \%$ \\
\hline 2015 & $17,67 \%$ & $5,92 \%$ & $8,70 \%$ \\
\hline 2016 & $17,12 \%$ & $5,81 \%$ & $9,80 \%$ \\
\hline Mean & $\mathbf{1 9 , 0 8 \%}$ & $\mathbf{1 2 , 5 7 \%}$ & $\mathbf{8 , 3 3 \%}$ \\
\hline \multicolumn{4}{|c|}{ Stabil dan besarnyan Nilai ROE }
\end{tabular}

yang dimiliki juga dapat dipengaruhi oleh besarnya CAR yang dimiliki suatu bank syariah. Semakin besar nilai CAR suatu bank syariah, maka akan semakin kuat modal yang dimilikinya. Jika modalnya semakin kuat, maka semakin kuat pula bank tersebut untuk melakukan ekspansi dan perluasan jaringannya guna menyalurkan pembiayaan. Sehingga nantinya bisa menghasilkan laba bersih yang tinggi. Hal ini sesuai dengan penelitian yang dilakukan oleh (Dewi, 2010). Tingginya ROE yang dimiliki oleh BIBD salah satunya dikarenakan oleh tingginya CAR yang dimiliki. 
Listiyanti, et al/Jurnal Ekonomi Syariah Teori dan Terapan Vol. 5 No. 12 Desember 2018: 1023-1027; KINERJA KEUANGAN BANK SYARIAH DI ASEAN

Nilai NPF juga merupakan variabel yang dapat mempengaruhi nilai ROE, karena NPF mencerminkan risiko pembiayaan. Semakin tinggi nilai NPF, menunjukan kualitas pembiayaan bank syariah yang buruk. Tentu saja hal tersebut akan berpengaruh terhadap pencapaian laba bank (Rosalia, 2011). Pada akhirnya pembiayaan adalah salah satu sumber terpenting bagi bank untuk menghasilkan keuntungan, sehingga kualitas pembiayaan bank akan sangat menentukan besar kecilnya laba yang didapatkan. Seperti halnya yang terjadi pada BSM, anjloknya nilai ROE yang dimiliki dikarenakan naiknya nilai NPF BSM sejak tahun 2013.

\section{Capital Adequacy Ratio}

\section{Tabel 8}

Nilai CAR pada BIMB, BSM, dan BIBD

\begin{tabular}{|c|c|c|c|}
\hline Tahun & BIMB & BSM & BIBD \\
\hline 2011 & $16,83 \%$ & $14,57 \%$ & $26,90 \%$ \\
\hline 2012 & $14,21 \%$ & $13,82 \%$ & $27,30 \%$ \\
\hline 2013 & $14,06 \%$ & $14,10 \%$ & $24,20 \%$ \\
\hline 2014 & $13,36 \%$ & $14,12 \%$ & $23,50 \%$ \\
\hline 2015 & $15,32 \%$ & $12,85 \%$ & $23,40 \%$ \\
\hline 2016 & $15,52 \%$ & $14,01 \%$ & $20,80 \%$ \\
\hline Mean & $\mathbf{1 4 , 8 8 \%}$ & $\mathbf{1 3 , 9 1 \%}$ & $\mathbf{2 4 , 3 5 \%}$ \\
\hline \multicolumn{4}{|c|}{ Berdasarkan uij ANOVA BIMB, BSM }
\end{tabular}

dan BIBD mempunyai perbedaan yang signifikan. Dimana BIBD memiliki nilai ratarata tertinggi. Hal ini dikarenakan Brunei Darussalam mempunyai regulasi tersendiri terkait dengan CAR. Regulator Brunei Darussalam mensyaratkan bank syariah mempunyai nilai ninimum CAR sebesar 20\%. Regulasi tersebut dimaksudkan untuk melindungi hak deposan dan nasabah apabila bank mengalami insolvable maupun hal-hal lain yang dapat mengganggu stabilitas bank.

Namun, secara keseluruhan diketahui bahwa ketiga bank syariah tersebut telah memenuhi standart minimum CAR berdasarkan basel III. Standart tersebut mensyaratkan bahwa untuk semua bank syariah mempunyai nilai CAR sebesar $8 \%$.

\section{SIMPULAN}

Berdasarkan hasil analisis dan interpretasi data yang dilakukan maka dapat diambil kesimpulan sebagai berikut:

1. Terdapat perbedaan kinerja keuangan yang signifikan antara BIMB, BSM, dan BIBD tahun 2011-2016 dengan menggunakan rasio NPF. Nilai NPF terendah dimiliki oleh BIMB.

2. Nilai rata-rata FDR menunjukan adanya perbedaan kinerja keuangan yang signifikan antara BIMB, BSM, dan BIBD tahun 2011-2016. BSM memiliki nilai rata-rata FDR tertinggi, hal ini mengindikasikan bahwa BSM sedang menerapkan tipe manajemen yang agresif untuk meningkatkan market share.

3. Kinerja keuangan antara BIMB, BSM, dan BIBD tahun 2011-2016 berdasarkan ROA tidak ditemukan adanya perbedaan yang signifikan .

4. Nilai rata-rata rasio ROE antara BIMB,BSM, dan BIBD tahun 2011-2016 menunjukan adanya perbedaan yang signifikan.

5. Adanya perbedaan kebijakan penentuan batas minimum nilai CAR pada masing-masing negara, 
Listiyanti, et al/Jurnal Ekonomi Syariah Teori dan Terapan Vol. 5 No. 12 Desember 2018: 1023-1027;

KINERJA KEUANGAN BANK SYARIAH DI ASEAN

menimbulkan adanya perbedaan yang signifikan pada kinerja keuangan antara BIMB, BSM, dan BIBD tahun 2011-2016 dengan menggunakan rasio CAR.

6. Penelitian ini berhasil menunjukan bahwa antara BIMB, BSM, dan BIBD memiliki perbedaan kinerja keuangan yang signifikan pada rasio NPF, FDR, ROE, dan CAR, sedangkan untuk rasio ROA tidak terdapat perbedaan yang signifikan. Tidak adanya perbedaan pada rasio ROA menunjukan bahwa BIMB mempunyai kualitas manajemen yang lebih bagus dan lebih efisien dibandingkan keduanya.

\section{DAFTAR PUSTAKA}

Alamsyah, Halim. 2012. Perkembangan dan Prospek Perbankan Syariah Indonesia: Tantangan dalam Menyongsong MEA 2015. Makalah disajikan dalam Ceramah Milad ke-8 Ikatan Ahli Ekonomi Islam. Jakarta.

Anshori, Muslich dan Sri Iswati. 2009. Buku Ajar Metodelogi Penelitian Kuantitatif. Surabaya: Airlangga Uiversity Press.

Antonio, Muhamad Syafi'i. 2007. Bank Syariah dari Teori ke Praktik. Jakarta: Gema Insani.

Box, G. E. P. 1954a. Some Theorems on Quadratic Forms Applied in the Study of Analysis of Variance Problems: I. Effect of Inequality of Variances in the One-way Classification. Annals of Mathematical Statistics, 25, 290-302.
Departemen Agama. 2010. Al-Qur'an dan Terjemahan. Bandung: Penerbit Hilal. Dewi, Dhika Rahma. 2010. Faktor-Faktor yang Mempengaruhi Profitabilitas Bank Syariah di Indonesia Periode 2005-2008. Skripsi tidak diterbitkan. Universitas Diponegoro.

Ghozali, Imam. 2011. Aplikasi Analisis Multivariate dengan Program IBM SPSS 19. Semarang: Universitas Diponegoro.

Ismail. 2011. Manajemen Perbankan: dari Teori menuju Aplikasi. Jakarta: Kencana.

Jumingan. 2006. Analisis Laporan Keuangan. Jakarta: PT Bumi Aksara.

Kasmir. 2008. Bank dan Lembaga Kevangan Lainnya. Jakarta: PT RajaGrafindo Persada.

$\mathrm{KFH}$ Research. 2013. Islamic Finance in Asia: Development, Growth, and Opporunities. Kuwait: Kuwait Finance House.

Lestari, Maharani Ika dan Toto Sugiharto. 2007. Kinerja Bank Devisa dan Bank Non Devisa dan Faktor-Faktor yang Mempengaruhinya. Jakarta: Universitas Gunadarma.

Muhamad. 2015. Manajemen Dana Bank Syariah. Jakarta: Raja Grafindo Persada.

Rosalia, Lia. 2011. Faktor-Faktor yang Mempengaruhi Profitabilitas Bank Syariah di Indonesia. Skripsi tidak diterbitkan. UIN Sunan Kalijaga Yogyakarta.

Saniati, Resti. 2015. Analisis Eksternal dan Internal dalam Menentukan Non 
Listiyanti, et al/Jurnal Ekonomi Syariah Teori dan Terapan Vol. 5 No. 12 Desember 2018: 1023-1027;

KINERJA KEUANGAN BANK SYARIAH DI ASEAN

Performing Financing pada Bank
Umum Syariah. Skripsi tidak
diterbitkan. UIN Sunan Kalijaga
Yogyakarta.

Santoso, Singgih. 2014. Statistik Multivariat.

Jakarta: Elex Media Komputindo.

Shihab, M. Quraish. 2009a. Tafsirisl AlMisbah. Vol. 2. Jakarta: Lentera Hati.

Srimindarti, C. 2006. Balanced Scorecard Sebagai Alternatif untuk Mengukur Kinerja. Semarang: STIE Stikubank.

Sukmana, Raditya \& Nur Ahlina Febriyati. 2016. Islamic Banks vs Conventional Banks in Indonesia: An Analysis on Financial Performances. Jurnal Pengurusan, Vol. 47, hlm. 81-90.

Wibowo, Susanto. 2015. Analisis Perbandingan Kinerja Keuangan Perbankan Syariah dengan Metode Camel di ASEAN (Studi Komparatif: Indonesia, Malaysia, Thailand). Journal of Research in Economics and Management, Vol. 15, No. 1, 2015, hlm. 136-153.

Webster, Allen L. 1998. Applied Statistics For Business and Economics: An Essentials Version. Singapore: Irwin McGrow-Hall.

\section{Regulasi}

Undang-Undang No. 21 Tahun 2008

SE OJK NO. 10/SEOJK.03/DPNP Tahun 2014

\section{Internet}

http://www.asean.org

http://www.bi.go.id

http://www.bibd.com.bn

http://www.bankislam.com.my

http://www.banksyariahmandiri.co.id http://www.bnm.gov.my

http://www.bps.go.id

http://www.ekbis.sindonews.com

https://www.ey.com

http://www.focus-economics.com

https://www.ifsb.com

http://www.indonesia-investments.com

https://www.kemenlu.go.id

https://www.ojk.go.id

https://www.rudiyanto.blog.kontan.co.id

https://www.sp2010.bps.go.id 